\title{
Come Together: Sports Medicine for Everybody-the 2021 American Medical Society for Sports Medicine issue
}

\author{
Katherine Rizzone ำ ,' Cynthia R LaBella ${ }^{2,3}$
}

This annual partnership issue from the American Medical Society for Sports Medicine (AMSSM) features the latest high-quality research and scholarship from AMSSM members. We also are excited to share the theme of the upcoming AMSSM annual meeting, 'Come Together: Sports Medicine for Everybody,' to be held from 13 to 18 April 2021 in San Diego, California.

\section{HIGHLIGHTS IN THIS ISSUE}

In 2019, AMSSM hosted the Youth Early Sports Specialization Summit. We are delighted to present a key product from that meeting, 'Defining a Research Agenda for Youth Sport Specialization: The AMSSM Youth Early Sport Specialization Summit' (see page 135). This summary statement reviews the current literature, identifies key findings, limitations and knowledge gaps, and outlines the priorities for future research on youth sport specialisation. Dr Joseph Baker provides an additional perspective on this topic in his commentary, 'Is it too early to condemn early sports specialization?' (see page 179).

AMSSM also presents an important position statement on 'Sexual Violence in Sport' (see page 132). In addition, this issue features a compelling patient voices article discussing personal experiences of sexual violence and a call to action for the sports and exercise medicine community: 'Helping athletes affected by sexual violence: my challenge to the sports and exercise medicine community' (see page 177).

We are living in a time of novel challenges related to the COVID-19 pandemic, but this also means we have a unique opportunity to advance the field of sports medicine to address this global event. Two of the articles, 'Infectious disease outbreak management tool for endurance mass participation sporting

${ }^{1}$ Orthopaedics, Rehabilitation and Pediatrics, University of Rochester Medical Center, Rochester, New York, USA ${ }^{2}$ Pediatrics, Northwestern University Feinberg School of Medicine, Chicago, Illinois, USA

${ }^{3}$ Pediatric Orthopedics and Sports Medicine, Ann \& Robert H. Lurie Children's Hospital of Chicago, Chicago, Illinois, USA

Correspondence to Dr Cynthia R LaBella, Pediatrics, Northwestern University Feinberg School of Medicine, Chicago, IL 60611, USA; clabella@luriechildrens.org

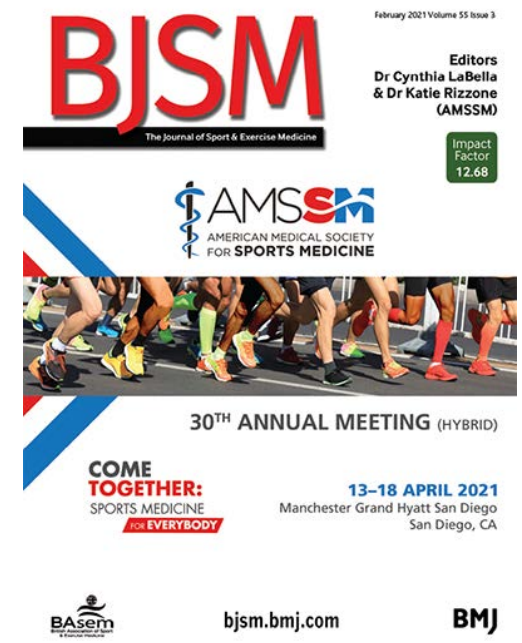

events. An international effort to counteract the COVID-19 spread in the endurance sport setting' (see page 181) from Dr Paolo Emilio Adami and colleagues, and 'Team sport in a COVID-19 world: A catastrophe in waiting or an opportunity for community sport to evolve and further enhance population health?' (see page 130) from Dr Steffan Griffin and colleagues describe how the pandemic has reshaped the way sports are played and how this change may ultimately have a positive impact on community health. The pandemic has also reshaped healthcare delivery in a positive way, with telemedicine services now being reimbursed for many types of sports medicine visits. A systematic review from Dr Jane Fonseca Dias and her colleagues examines the effectiveness of telerehabilitation exercises on individuals with physical disabilities (see page 155).

This issue also includes original research that advances our knowledge of sport-related injuries in competitive athletes. The acute and chronic impacts of sports-related concussion on athletes' cerebral cortices are presented by the NCAA-DOD CARE Consortium in its large prospective study of collegiate athletes (see page 169). Dr David Kruse and his colleagues explore injury incidence in male artistic gymnasts, an infrequently studied population of athletes (see page 163).

Lastly, two articles, 'Fit for life? The burden of future disability associated with a low cardiorespiratory fitness in adolescence' (see page 128) from Dr Pontus Henriksson and colleagues and 'Effects of sedentary behaviour interventions on markers of cardiometabolic risk in adults: systematic review with meta-analyses' (see page 144) from Dr Paddy Dempsey and colleagues, examine the negative health effects of sedentary behaviour and how establishing healthy behaviours during childhood and adolescence result in long-term benefits.

\section{AMSSM ANNUAL MEETING IN SAN}

\section{DIEGO, 13 TO 18 APRIL 2021}

Widespread change and uncertainty, while disruptive and stressful, can also unite us under a common goal to build a better future for all. This reflects the theme of the upcoming AMSSM annual meeting, 'Come Together: Sports Medicine for Everybody,' which will present core topics, such as return to play, osteoarthritis and nutrition, but from a variety of perspectives to highlight the AMSSM values of diversity, inclusion and equity. One plenary session will focus on sexual violence in sport led by Dr Jennifer Koontz. An added attraction to the annual meeting will feature the 'AMSSM Physical Activity and Exercise Medicine Summit: Advancing Education, Clinical Practice, and Research for the Sports Medicine Physician.' This research summit sponsored by the AMSSM Collaborative Research Network will focus on medical and fellowship education on exercise medicine and the clinical practice models that best promote physical activity, as well as identify knowledge gaps and research priorities for the future.

While the format for the AMSSM annual meeting may be altered by the COVID-19 pandemic, we welcome you to join us (in-person or remotely) for an inspiring and educational conference.

Contributors Both authors contributed equally to this submission.

Funding The authors have not declared a specific grant for this research from any funding agency in the public, commercial or not-for-profit sectors.

Competing interests None declared.

Patient consent for publication Not required.

Provenance and peer review Commissioned; internally peer reviewed.

(c) Author(s) (or their employer(s)) 2021. No commercial re-use. See rights and permissions. Published by BMJ.

\section{(A) Check for updates}

To cite Rizzone K, LaBella CR. Br J Sports Med 2021;55:127.

Accepted 18 November 2020

Br J Sports Med 2021;55:127

doi:10.1136/bjsports-2020-103718

\section{ORCID iD}

Katherine Rizzone http://orcid.org/0000-0002-30302638 